\title{
(i) caran \\ ○ \\ OPEN ACCESS \\ Innovative approach to open abdomen: converting an enteroatmospheric fistula into an easily manageable stoma
}

\author{
Michael Ron Freund (1) , Petachia Reissman, ${ }^{1}$ Ram M Spira, ${ }^{1}$ Moris Topaz ${ }^{2}$
}

${ }^{1}$ Department of General Surgery, Shaare Zedek Medical Center, The Hebrew University School of Medicine, Jerusalem, Israel ${ }^{2}$ IVT Medical Ltd, Ra'anana, Israel

Correspondence to Dr Moris Topaz: mtopazmd@yahoo.com

Accepted 9 July 2020
Check for updates

(c) BMJ Publishing Group Limited 2020. Re-use permitted under CC BY-NC. No commercial re-use. See rights and permissions. Published by BMJ.

To cite: Freund MR Reissman P, Spira RM, et al. BMJ Case Rep 2020:13:e234207 doi:10.1136/bcr-2019234207

\section{SUMMARY}

A 52-year-old super morbidly obese patient underwent elective laparoscopic conversion of a failed silastic ring vertical gastroplasty to a Roux-en-Y gastric bypass. Following surgery, she developed an anastomotic leak which required emergent laparotomy. The patient then suffered from a complex postoperative course during which she developed an intestinal fistula which freely drained into the wound and gradually led to its complete dehiscence. Her course was further complicated by the surfacing of an enteroatmospheric fistula. This devastating complication was managed by employing the TopClosure Tension Relief system. Using the inverse maturation technique, further described in this report, we were able to progressively approximate and invert the edges of the skin around the enteroatmospheric fistula, thereby facilitating its conversion to an easily manageable stoma. Using this technique, we were able to achieve delayed primary wound closure of a grade 4 open abdomen complicated by an enteroatmospheric fistula in just under 5 weeks' time.

\section{BACKGROUND}

Enteroatmospheric fistula (EAF) is a devastating complication of abdominal surgery. It has become more prevalent in recent years due to the widespread implantation of the 'damage control' doctrine in trauma and acute care surgery. Although some progress has been made regarding treatment of this dreadful complication, effective treatment of EAF remains lacking and current management techniques do not seem to meet the challenging needs of these complex wounds. In this report, we present a novel technique in which complete delayed primary wound closure is achieved through relatively fast gradual approximation of the wound edges around the orifice of the fistula, until its eventual maturation, thus transforming it into a stoma de facto. This technique is unique because it challenges the conventional approach to wound healing as it facilitates delayed primary wound closure of a heavily contaminated wound, essentially omitting the granulation phase and obviating the need for any future skin graft or complex reconstructive procedures.

\section{CASE PRESENTATION}

A 52-year-old super morbidly obese female patient with a body mass index (BMI) of $52 \mathrm{~kg} / \mathrm{m}^{2}$ underwent elective laparoscopic conversion of a failed silastic ring vertical gastroplasty to a Roux-en-Y gastric bypass. Following an initial, uneventful postoperative week, she developed a small-bowel obstruction due to incarceration of a loop of the small bowel in a previously asymptomatic umbilical hernia. This incarceration led to severe proximal dilatation, to breakdown of the jejunojejunal anastomosis and to a leak from the gastrojejunal anastomosis. During an emergency laparotomy, reanastomosis of the jejunojejunal anastomosis was undertaken, drains were positioned in proximity to both anastomoses and a jejunostomy tube was placed distally for future feeding. To avoid abdominal compartment syndrome, the fascial edges were left separated and only the skin primarily closed. Following recovery from a prolonged septic course, the patient developed a fistula originating from a leak in the reconstructed jejunojejunal anastomosis, which freely drained into the surgical wound and gradually led to septic dehiscence of the entire transverse laparotomy incision (figure 1). At this stage (26 days after the emergency laparotomy), we were faced with a significant challenge: a super morbidly obese patient with a grade 4 open abdomen (OA), complicated by a high-output EAF. ${ }^{1}$ Furthermore, the exposed bowel had firmly adhered to the base of the wound and the fascia had undergone complete lateral retraction, making conventional surgical closure virtually impossible.

\section{TREATMENT}

The TopClosure Tension Relief System (TRS) (IVT Medical, Ra'anana, Israel) is an innovative method originally designed for skin stretching and secure wound closure. ${ }^{2}$ It has also previously been applied to enable primary closure of large soft tissue defects. ${ }^{3}$ The system comprises two malleable polymer attachment plates (APs) that are fixed to the skin with an adhesive material and secured by skin staples or sutures over an extensive area of adherence. The APs are placed at a distance from the wound margins, and are gradually pulled together by flexible approximation straps (AS), interconnected through a lock and release ratchet mechanism, which serve to incrementally advance the wound edges. The APs also serve as a tension relief platform for tension sutures, by protecting the underlying skin when high tension is applied, such as in closure of large skin gaps. The system enables application of a large mechanical force (up 


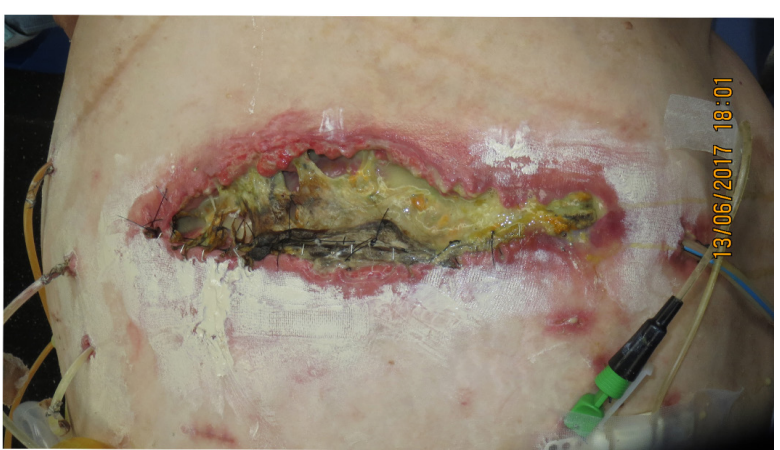

Figure 1 Postoperative day 0: septic dehiscence of the transverse laparotomy incision.

to $60 \mathrm{~N}$ ), thus facilitating immediate primary wound closure while inflicting up to five orders of magnitude of less tension on the skin, compared with conventional suturing. ${ }^{3}$ Delayed primary closure can be achieved through gradual postoperative approximation of the skin, by pulling on the AS. Multiple sets of APs can be applied perpendicular to the wound to accommodate selective local vectors of tension along the wound margins, thus fitting a wide variety of wounds. Regulated negative pressure-assisted wound therapy (RNPT) is an established technology that promotes cure of hard to heal wounds. RNPT applies subatmospheric pressure to the wound, which induces angiogenesis, granulation tissue growth and constant active flow of lymphatic fluids and bacteria out of the wound. ${ }^{4}$ Reduced partial pressure of oxygen $\left(\mathrm{PO}_{2}\right)$ levels are an inherent physical phenomenon in wound environments treated by RNPT, limiting its use in apparent or suspected anaerobic infections. RNPT has been previously upgraded by the simultaneous administration of supplemental irrigation and oxygen, as was demonstrated in the treatment of necrotising fasciitis. ${ }^{5}$ This technique, termed regulated irrigation and oxygen-enriched negative pressure-assisted wound therapy (ROI-NPT), effectively evacuates infective materials and combats anaerobic infection, thus enabling delayed primary closure of contaminated wounds when synergistically applied with TRS.

On septic dehiscence of the transverse laparotomy incision, the patient underwent rapid volume restoration and correction of electrolyte imbalance and was promptly transferred to the operating room for staged surgical attempts to close the abdominal wall and control the EAF. For simplicity purposes, we refer to this day as postoperative day (POD) 0 .

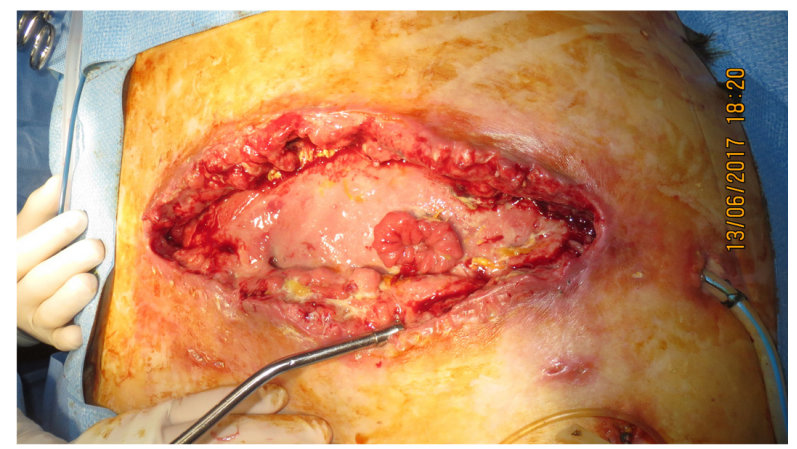

Figure 2 Postoperative day 0: debridement and cleansing exposed a loop of small bowel firmly adherent to the base of the wound with an enteroatmospheric fistula (protruding mucosa) off-center on the left.

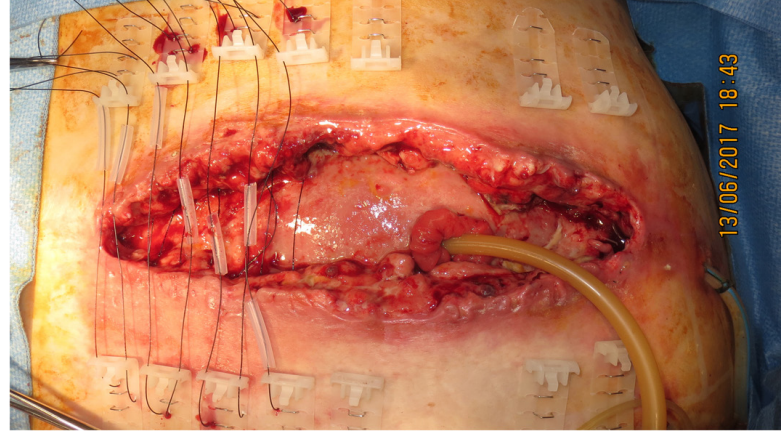

Figure 3 Postoperative day 0: multiple attachment plates with nylon tension sutures aligned and placed perpendicular to the wound. The cannulated enteroatmospheric fistula is seen off-center on the left of the wound.

\section{Stage 1 (POD 0)}

After initial conservative surgical debridement of the wound and thorough irrigation with saline, 5\% diluted povidoneiodine solution and $1.5 \%$ hydrogen peroxide (figure 2), APs were attached to both sides of the wound, $3-4 \mathrm{~cm}$ away from the wound margins, using skin staples (WECK Vista, Teleflex Medical, North Carolina, USA). Two nylon 1 tension sutures with long $(90 \mathrm{~mm})$, sharp needles were inserted through the designated opening of the APs, through the deep layer of the skin above the fascia and out into the opposite side of the wound to penetrate the plate on the other side. Although intubating a fistula in the middle of an OA is generally not recommended (as it often enlarges the opening of the fistula), we inserted a Foley catheter inside the lumen of the EAF for diversion of the enteric contents, as our goal was not to close the EAF but rather its gradual maturation into an easily manageable stoma (figure 3 ). An irrigation catheter was placed deep in the left lateral wound cavity and secured to the skin with staples. Wound margins were approximated en bloc, in stages, by tension sutures passed through the APs. (figure 4). A duble-layer polyurethan open-cell sponge, coated with non-permeable polyurethane layer (IVT Medical), was placed directly over the wound, under the tension sutures, to avoid direct attachment of the open-cell sponge with the bowel. Another sponge was placed around the Foley catheter to evacuate intestinal leak around the catheter (figure 5A). The wound was then covered with a second layer of sponge, sealed at its edges with a drape, and treated by cyclic continuous mode (40-60 $\mathrm{mmHg}$ range) ROI-NPT. Continuous irrigation (normal saline $0.9 \%)$, oxygen $\left(100 \% \mathrm{O}_{2}, 0.5 \mathrm{~L} / \mathrm{min}\right)$ were introduced

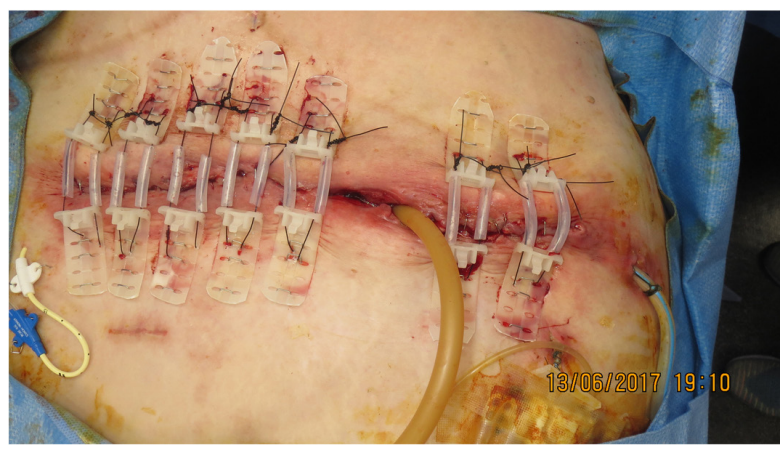

Figure 4 Postoperative day 0: initial approximation of the attachment plates and wound edges. An irrigation catheter (on the left) placed deep in the wound cavity and secured to the skin by staples. 

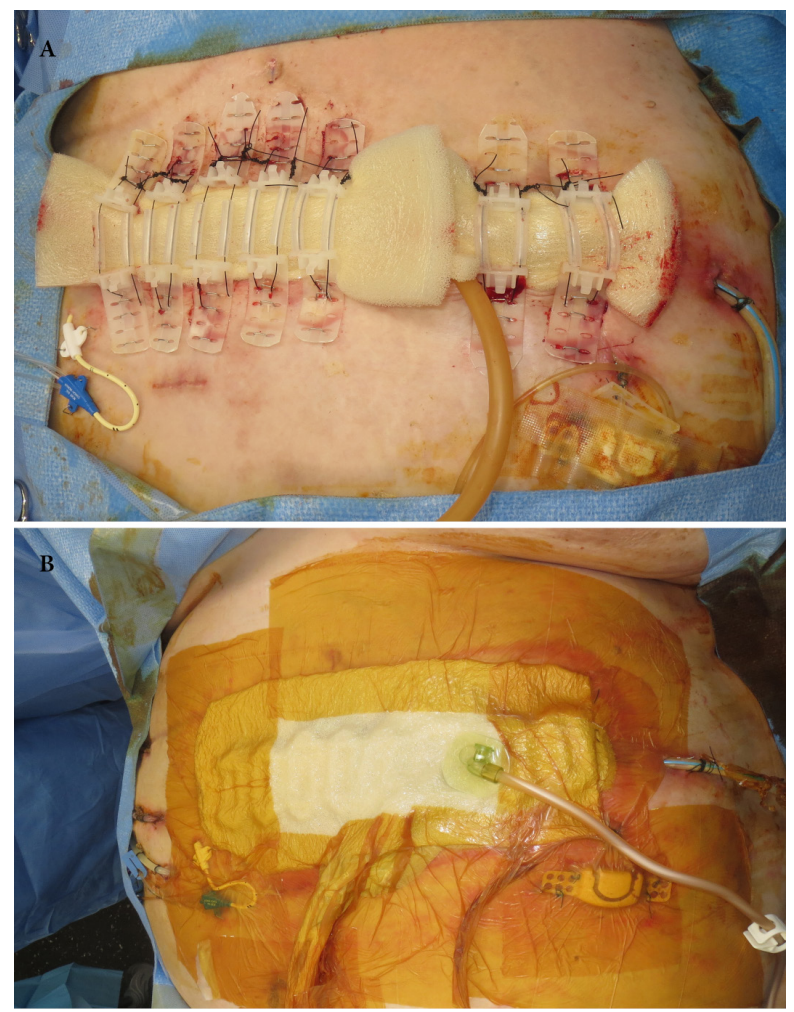

Figure 5 (A) Dressing of the wound in layers: the double layered open-cell foam was placed directly over the wound, with its nonpermeable surface facing down, under the tension sutures, to avoid direct contact of the open-cell sponge with the bowel. Another sponge was placed around the Foley catheter to evacuate intestinal leak around the catheter. (B) The wound sealed at its edges with a sterile drape and treated by continuous regulated irrigation and oxygen-enriched negative pressure-assisted wound therapy system.

through their designated inlets and connected to the Vcare $\alpha$ vacuum system (IVT Medical) (figure 5B).

\section{Stage 2 (POD 4)}

Exploration of the wound revealed mild, superficial skin irritation, yet no exacerbation of the necrotic process (figure 6A). The wound was again thoroughly irrigated with no further debridment necessary. A specialised stoma sticker attached to a convex barrier ring was placed around the EAF to protect the surrounding skin from irritating enteric contents (figure 6B), while another strip of foam was rolled and laid over the first layer of sponge and under the tension sutures and AS (figure 7). By pulling on the flexible AS, perpendicular compression of the wound was generated, fully obliterating the dead space under the skin and inverting the edges of the skin along sides of the fistula (figure 8). ROI-NPT dressings were reapplied and were changed every 4-6 days until gradual closure of the wound and eventual stoma maturation.

After the wound edges completely adhered around the EAF (POD 30), vicryl 3-0 sutures were used to attach the protruding mucosa to the edges of the skin in order to complete its conversion into a mature stoma (figure 9). Stoma care, provided by our dedicated stoma nurse, involved special tailoring of the stoma base device to properly fit the unique and challenging needs of the wound. During the entire length of treatment, the patient was maintained nil per os and received enteral nutrition support (peptide-based formulas) via feeding jejunostomy tube. She was
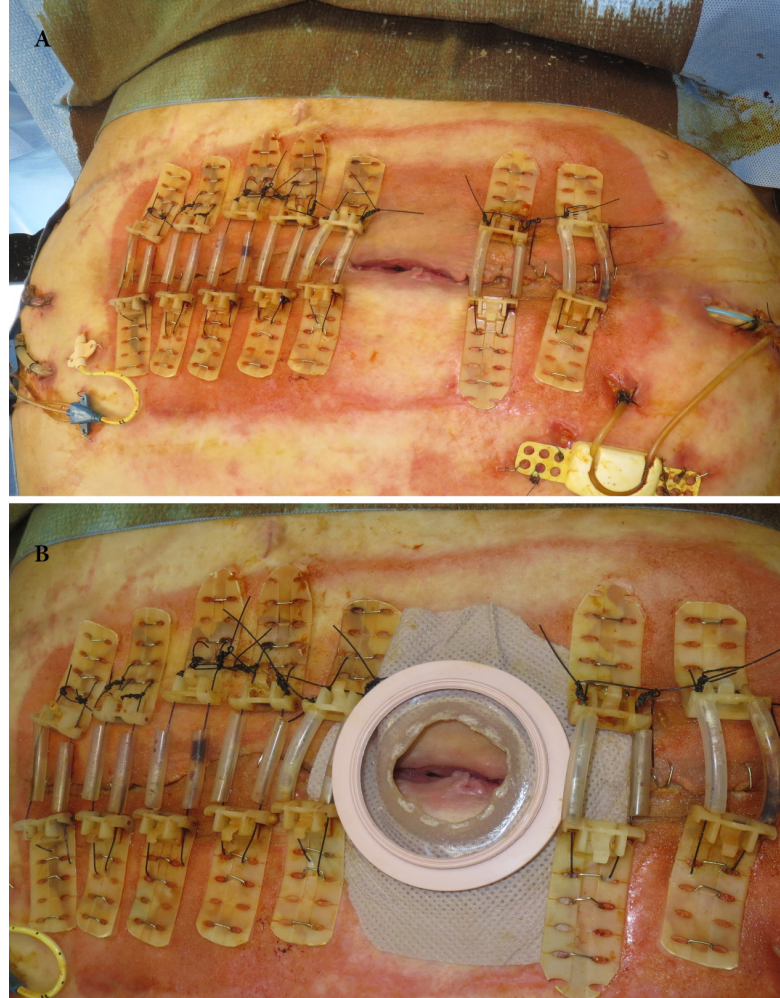

Figure 6 Postoperative day 4. (A) Mild, superficial skin irritation and viable wound margins were observed. (B) A specialised stoma sticker attached to a convex barrier ring was placed around the orifice of the enteroatmospheric fistula to protect the surrounding skin from enteric contents.

kept in good nutritional state with persistent albumin levels of over $3.5 \mathrm{~g} / \mathrm{dL}$ throughout her admission. All surgical procedures were performed under general anaesthesia in order to achieve maximal muscle relaxation and avoid patient discomfort. Local skin irritation induced by the corrosive enteric contents was managed with topical cream.

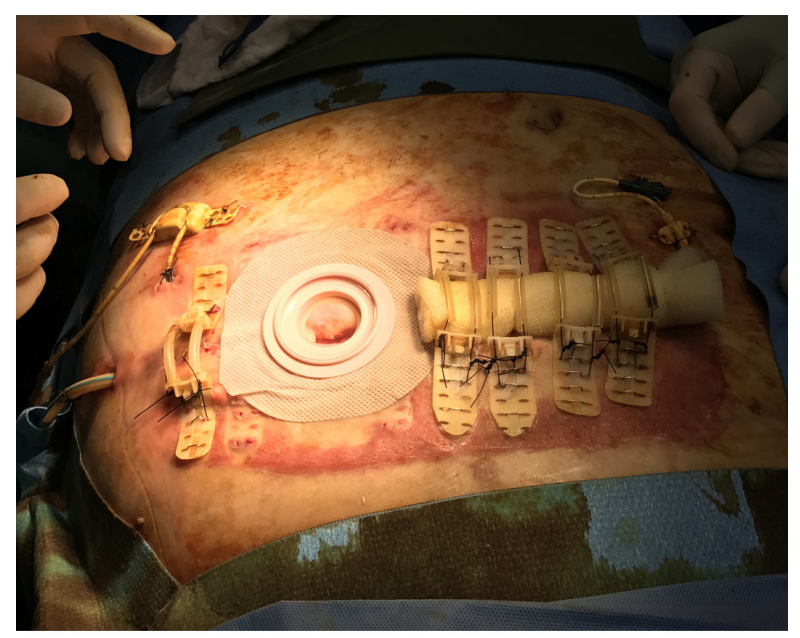

Figure 7 By placing rolls of sponge under the tension sutures and approximation straps, topical pressure was applied on the wound margins. 


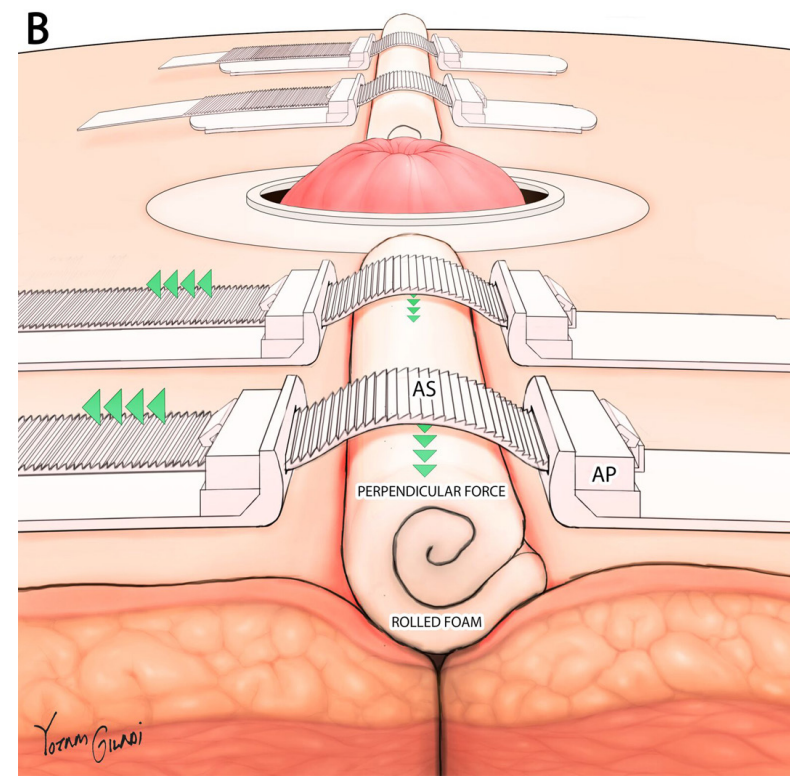

Figure 8 Schematic representation of the inverse maturation technique. A roll of foam is laid under the attachment straps. Pulling on the flexible attachment straps generates mild perpendicular compression of the wound area, thereby fully obliterating the dead space under the skin and inverting the edges of the skin along the sides of the fistula. (The illustration was designed by Mr Yotam Giladi. The authors maintain copyright ownership of the above drawing.).

\section{OUTCOME AND FOLLOW-UP}

The patient completed closure of her abdominal wall as mentioned on POD 30. She was later discharged on POD 50 after tolerating regular oral diet. She was followed up by our team and had her stoma closed 6 months later. She came back a year later again for open mesh repair of the incisional hernia that formed later and is currently doing well without any recurrence.

\section{DISCUSSION}

The widespread use in recent years of the 'damage control' doctrine in trauma and emergency surgery has resulted in higher prevalence of $\mathrm{OA}$ and has also given rise to the dreaded complication of the EAF. $^{6}$ Although some progress has been made regarding treatment and care of this rare, yet life-threatening complication, the effective treatment of EAF remains lacking and still carries a high mortality rate $(20 \%-44 \%) .^{78}$ Many different temporary and permanent closure techniques for OA after trauma or abdominal sepsis have been proposed over the years such as the Bogota bag, ${ }^{9}$ the Wittmann patch, the floating stoma ${ }^{10}$ and various vacuum-assisted wound management systems, ${ }^{11}$ but none has been shown to effectively meet the challenging needs of these complex wounds. ${ }^{12}$ Moreover, the goal of all of these techniques is to achieve secondary wound healing by controlling outflow of intestinal contents. As a result, they inherently entail a prolonged healing period to allow for adequate granulation tissue growth over the entire wound bed, followed by skin grafting and additional complex reconstructive procedures, usually $6-12$ months later. ${ }^{13}$ We present a novel technique in which delayed primary wound closure is achieved through a relatively fast, gradual approximation of the wound edges around the EAF, until its eventual maturation, thus transforming it into a stoma de facto (figure 10). We employed the inverse maturation technique in which the skin is approximated to the orifice of the fistula by pulling on the wound edges, thus facilitating formation of a mature stoma, whereas the conventional method for stoma

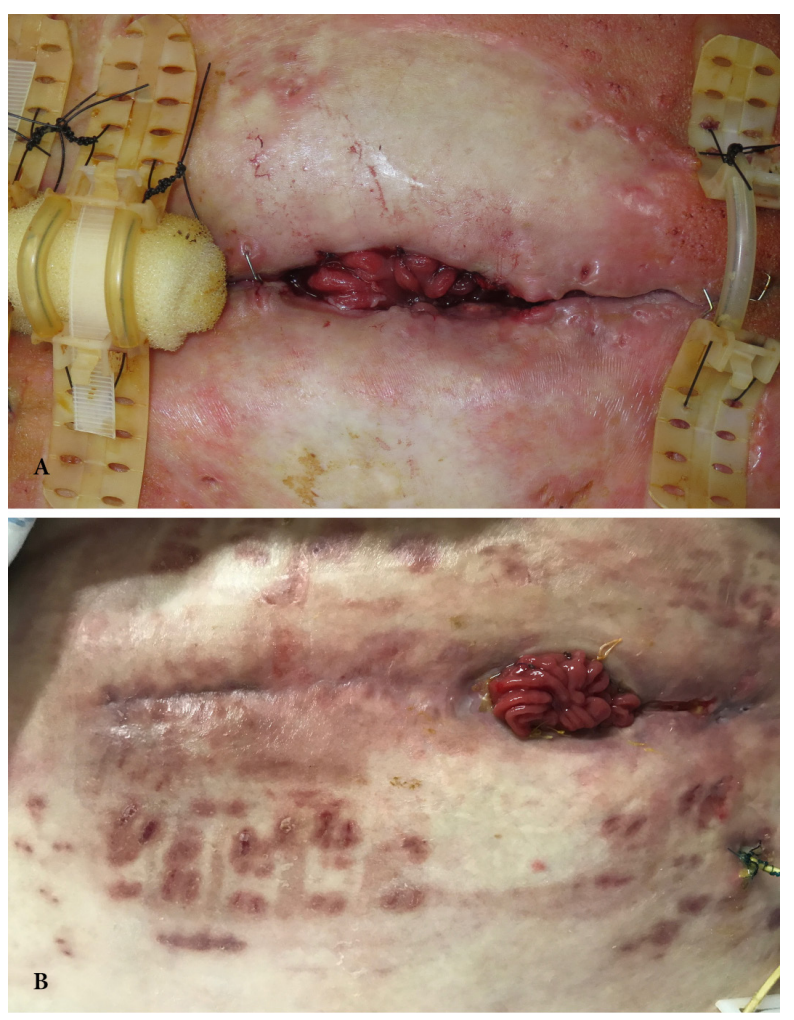

Figure 9 (A) The wound showing near-complete closure. (B) Complete closure of the wound with with transformation of the enteroatmospheric fistula into a full mature stoma. Note some miled pigmentation changes of the skin at the location of the attachment plates.

maturation entails the approximation of the bowel edges to the skin. Keeping in mind that the skin is the best dressing, this technique challenges the conventional approach to wound healing as it facilitates primary wound closure of a complex and heavily contaminated wound in a relatively short period of time. While other vacuum-based treatments focus on enhancing the classical angiogenesis and granulation phase, our technique in effect omits this phase allowing for the delayed primary closure and obviating the need for any skin graft or complex reconstructive procedures. ${ }^{14}$

The TopClosure ${ }^{\circledR}$ TRS distributes the forces needed to approximate the skin over a relatively wide area of skin, away from the inflamed and often mutilated wound edges, thus enabling application of significant traction forces to the skin with minimal sheer stress, avoiding ischemia, considerable skin damage, and pain, ${ }^{2}$

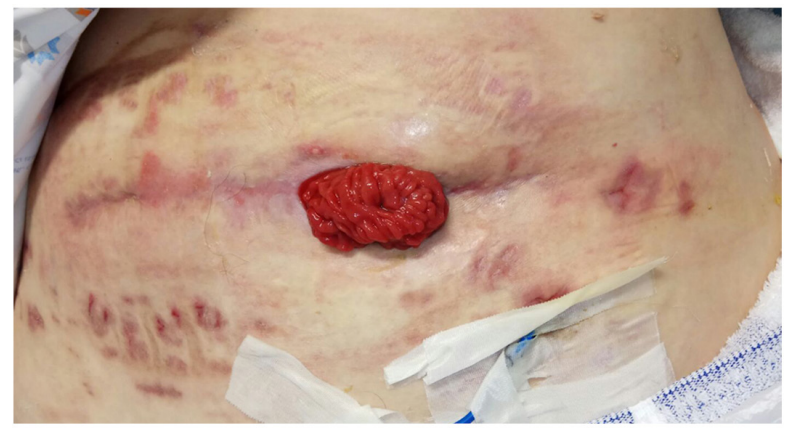

Figure 10 Complete closure of the wound and maturation of the enteroatmospheric fistula in a fully established stoma achieved in 5 weeks' time. 
whereas other skin suturing techniques are prone to necrosis and evisceration, due to excessive tension. ${ }^{15}$ Traditionally, OA was managed as a planned ventral hernia, usually repaired by an additional operation many months later. ${ }^{16}$ This new approach focuses on achieving relatively fast delayed primary wound closure and EAF management during the same admission. Although in this case, the TopClosure TRS was placed late in the sequence of wound treatment, after the fascia already underwent complete lateral retraction, had it been applied earlier and attached effectively to the fascia, it may have prevented fascial lateral retraction. Early placement during the initial 'damage control' surgery may allow for later gradual approximation and delayed primary closure, including the fascial layer, thus preventing the formation of a postoperative ventral hernia.

In conclusion, the inverse maturation closure technique represents a modern approach to an early definitive wound closure and provides a simple and elegant solution to a complex surgical problem.

\section{Patient's perspective}

Lying in bed with my entire surgical wound wide open and foulsmelling discharge oozing out I just could not believe I would ever make it out of the hospital. I weighed $150 \mathrm{~kg}$ and have been admitted for almost 2 weeks straight having already underwent two major operations. I remember the surgeons telling me about the fistula I developed, and from reading a little bit about it online it seemed that there is no real way to permanently close it . When the surgeons proposed their plan to convert the fistula into a stoma, I was unsure at first but decided to put faith in them and attempt this technique. Looking back, 2 years from now, I have lost $85 \mathrm{~kg}$, the stoma has been long closed and I feel and look healthy. I only have the team of doctors and nurses that took care of me to thank. I hope this technique gains widespread acceptance so it could help other patients in similar difficult situations.

\section{Learning points}

- Delayed primary wound closure of a complex and heavily contaminated abdominal wound can be facilitated in a relatively short period of time using the TopClosure Tension Relief System (TRS).

- Using the inverse maturation technique, described in this report, it is possible to convert an enteroatmospheric fistula into an easily manageable stoma in a relatively short period of time.

- Early placement of the TopClosure TRS and effective attachment to the fascia during the initial 'damage control' surgery may allow for gradual delayed primary closure.
Acknowledgements We would like to thank Mr Yotam Giladi for his help with the design and graphics of the artwork.

Contributors MRF: conception and design of the manuscript, writing and revising the manuscript, and literature review. MT: conception and design of the manuscript, and writing, editing and revising the manuscript, images and graphics. PR and RMS: editing and revising the manuscript.

Funding The authors have not declared a specific grant for this research from any funding agency in the public, commercial or not-for-profit sectors.

Competing interests MT is the inventor of the TopClosure Tension Relief System and the Vcare $\alpha$ systems, and CEO of IVT Medical Ltd, manufacturing the devices.

\section{Patient consent for publication Obtained.}

Provenance and peer review Not commissioned; externally peer reviewed.

Open access This is an open access article distributed in accordance with the Creative Commons Attribution Non Commercial (CC BY-NC 4.0) license, which permits others to distribute, remix, adapt, build upon this work non-commercially, and license their derivative works on different terms, provided the original work is properly cited and the use is non-commercial. See: http://creativecommons.org/ licenses/by-nc/4.0/.

ORCID iD

Michael Ron Freund http://orcid.org/0000-0002-3733-9628

\section{REFERENCES}

1 Björck M, Bruhin A, Cheatham M, et al. Classification--important step to improve management of patients with an open abdomen. World I Surg 2009;33:1154-7.

2 Topaz M, Carmel N-N, Silberman A, et al. The TopClosure $₫ 35$ system, for skin stretching and a secure wound closure. Eur J Plast Surg 2012;35:533-43.

3 Topaz M, Carmel N-N, Topaz G, et al. A substitute for skin grafts, flaps, or internal tissue expanders in scalp defects following tumor ablative surgery. J Drugs Dermatol 2014;13:48-55.

4 Argenta LC, Morykwas MJ. Vacuum-assisted closure: a new method for wound control and treatment: clinical experience. Ann Plast Surg 1997;38:563-77.

5 Topaz M, Bisker O, Litmanovitch M, et al. Application of regulated oxygen-enriched negative pressure-assisted wound therapy in combating anaerobic infections : Oxygen-enriched negative pressure treatment. Eur J Plast Surg 2011:34:351-8.

6 Hirshberg A, Walden R. Damage control for abdominal trauma. Surg Clin North Am 1997:77:813-20.

7 Martinez JL, Luque-de-Leon E, Mier J, et al. Systematic management of postoperative enterocutaneous fistulas: factors related to outcomes. World I Surg 2008:32:436-43.

8 Tavusbay C, Genc H, Cin N, et al. Use of a vacuum-assisted closure system for the management of enteroatmospheric fistulae. Surg Today 2015;45:1102-11.

9 Mattox KL. Introduction, background, and future projections of damage control surgery. Surg Clin North Am 1997;77:753-9.

10 Subramaniam MH, Liscum KR, Hirshberg A. The floating stoma: a new technique for controlling exposed fistulae in abdominal trauma. J Trauma 2002;53:386-8.

11 Roberts DJ, Zygun DA, Grendar J, et al. Negative-pressure wound therapy for critically ill adults with open abdominal wounds: a systematic review. J Trauma Acute Care Surg 2012;73:629-39.

12 Cirocchi R, Birindelli $A$, Biffl WL, et al. What is the effectiveness of the negative pressure wound therapy (NPWT) in patients treated with open abdomen technique? A systematic review and meta-analysis. J Trauma Acute Care Surg 2016;81:575-84.

13 Bobkiewicz A, Walczak D, Smoliński S, et al. Management of enteroatmospheric fistula with negative pressure wound therapy in open abdomen treatment: a multicentre observational study. Int Wound I 2017;14:255-64.

14 Stadelmann WK, Digenis AG, Tobin GR. Physiology and healing dynamics of chronic cutaneous wounds. Am J Surg 1998;176:26S-38.

15 Rutherford EJ, Skeete DA, Brasel KJ. Management of the patient with an open abdomen: techniques in temporary and definitive closure. Curr Prob/ Surg 2004:41:821-76

16 Fabian TC, Croce MA, Pritchard FE, et al. Planned ventral hernia. Staged management for acute abdominal wall defects. Ann Surg 1994;219:643-53. 
Copyright 2020 BMJ Publishing Group. All rights reserved. For permission to reuse any of this content visit https://www.bmj.com/company/products-services/rights-and-licensing/permissions/

BMJ Case Report Fellows may re-use this article for personal use and teaching without any further permission.

Become a Fellow of BMJ Case Reports today and you can:

- Submit as many cases as you like

- Enjoy fast sympathetic peer review and rapid publication of accepted articles

- Access all the published articles

- Re-use any of the published material for personal use and teaching without further permission

Customer Service

If you have any further queries about your subscription, please contact our customer services team on +44 (0) 2071111105 or via email at support@bmj.com.

Visit casereports.bmj.com for more articles like this and to become a Fellow 